\title{
Future World: Anticipatory archaeology, materially-affective capacities and the late human legacy
}

\section{Danger! Keep out! Do not enter!}

We consider ourselves a very potent civilisation

If we succeed ONKALO may well be the lasting remains of our civilisation

If you find this - what will it tell you about us? Into Eternity, 2010

Archaeology, as traditionally defined, is the study of the human past through its material remains. Increasingly, it is moreover seen as a practice both in and of the present, in its literal (e.g. Buchli and Lucas 2001; González-Ruibal 2013; Graves-Brown et al. 2013; Harrison 2011) and metaphoric (e.g. Foucault 2002; Freud 1959; Sloterdijk 2011a) capacity to unravel that which is hidden, repressed or silenced. In this article, however, we want to think about archaeology from a different perspective: the potential for archaeology to address what is to come. We argue that a future, anticipatory, archaeology can open up spaces for us to think through questions around the shared materiality of the human and what may come after the human, doing so through creative reference to the film Into Eternity (2010). Through this anticipatory archaeology, we wish to claim the possibility for human beings to actually connect over time and space, be it backwards (as in traditional archaeology) or forwards (archaeological thinking applied to contemporary efforts to communicate with future human communities, in this case through the problem of radioactive waste storage).

Into Eternity, by the filmmaker and conceptual artist Michael Madsen, concerns the ONKALO project, a vast nuclear waste repository in Finland currently under construction. The deep geological repository runs five kilometres underground and consists of a network of tunnels bored 
into stable magnetic gneiss bedrock and employs materials ranging from cast iron and copper to precompressed bentonite clay to contain the high-level radioactive waste, such as spent fuel rods, and seal it away. When the waste has been deposited, the tunnels will be sealed with concrete and the repository will be left to itself - 'abandoned', so to speak. ONKALO is not expected to be completed until well into the 2100s. Some of the various isotopes contained within the waste within ONKALO will stay dangerous to life for over 100,000 years, and deep geological storage is now accepted as being the only long term means of storing high-level waste. The long half-lives of many of the isotopes present, for example Uranium 238, mean that solutions involve contemplating the distant future, as well as the safety of our immediate descendants.

The film is a meditation on time, duration, futurity and humanity, drawing our attention to the impossibility of knowing what and how future worlds may be inhabited, and also to the figure of the archaeologist/inhabitant of the future. The subject matter of Into Eternity has been described as 'nothing less than post-human architecture' (Bradshaw 2010, 8). Madsen's voiceover addresses the inhabitants of the future, questioning what they feel, understand and know, and much of the film is concerned with the problem of how to communicate the perils of the repository across almost unimaginably vast timespaces.

The problem of alerting distant future inhabitants of the world to the radioactivity contained within such waste repositories invites us to consider what it means to be human, or to be human-like. An identification of the ways in which contemporary 'experts' speculate on the inhabitants of the future provides an interesting lens for approaching the concerns of the present: for considering what is currently held to be precious or important. It requires us to ask what we share, how we differ, and what common ground can enable us to speak across millennia. These are the questions that archaeologists implicitly, and occasionally explicitly, engage with when looking in the opposite temporal direction. Into Eternity invites both the question of how to imagine and communicate with 
the unknowable Other, and how to interrogate the assumptions that are made about what might be shared and what remains recognisable. Our reading of the film makes visible the assumptions made about the embodied capacities of the inhabitants of the future in the film: for example to access language and semiotic codes, to experience through the senses, to be vulnerable to radioactivity and to wish to avoid pain and death.

We engage with Into Eternity as both a vehicle for thought and a means of illustrating some of the ideas and arguments we make in the article. Rather than critiquing the film, we adopt it as our starting point, a provocation, for critical reflection on a range of archaeological concerns, and how the questions, scenarios, landscapes and figures in the film trigger meditations on the possibility of relating to a distant Other via the material legacies of the nuclear age. We address these concerns through contemporary theoretical orientations, specifically those that call into question the specificity of the human. In doing so we suggest that bodies (of people and things) are mutually emergent through affective relationships, but also that we need to maintain the idea of the human in order to appreciate the particular qualities of human bodies and embodiments in all of their heterogeneity. In this way we offer an engagement with a specific set of theoretical framings in order to think about some of these issues, to experiment with an archaeology of the future and to ask, what becomes of the 'modern' human in the light of the post-human turn?

To engage with this question the article takes the following structure: First, we outline what is meant by 'post-humanism' and argue that a tentative 'return to the human' may now be a productive route. We suggest, however, that some recent calls (e.g. Simonsen 2013) to return to the human via phenomenology may be problematic. We consider instead how the filmic landscapes of Into Eternity enable us to think through the problems with such forms of humanism, and offer an analysis of the production of the human as represented in the film, extracting a number of points of connection through which we can try to think across millennia. This engagement with Into Eternity, 
as we will see, creates a space for further critical reflection that emphasises the need to consider how a materially-affective archaeology, drawing on the philosophy of Deleuze and Spinoza on the one hand, and Sloterdijk on the other, can move the problem of a sensing, feeling Being beyond the human, and enable us to think about what we might hold in common across distant timespaces.

\section{Post-human thought}

Into Eternity moves between interviews with professionals involved with the ONKALO project, sweeping steadicam shots of the site, and intimate images of the lives of the contract workers. ONKALO is pictured as visual spectacle, as the camera dollies over the vast facility - the dark tunnels, the clean white spaces where waste is held in temporary storage, the huge machines that work on the excavations of the tunnels, and over the sparse, Finnish landscape. Some shots are reminiscent of Stanley Kubrick's 2001: A Space Odyssey (1968), fetishizing what we might consider a technological sublime, while other parts evoke the desolate and post-industrial landscapes of Andrey Tarkovsky's Stalker (1979). The filmic world is represented as a complex assemblage of machinery, rock, animals, laboratories, scientists, artists, workers, snow, trees, portakabins. At one point in the film the sound of the rock blasting enters the steadicam footage of the forest. Reindeer look up, then return to their grazing. The camera moves from human to non-human, mutually embroiling them in a shared project of care for the future: the legacy of the nuclear age.

The film raises a wide variety of questions as to the place of the human as a body amongst bodies: about where the human is in the midst of this busy, vibrant world. Is there a place for it? What forms of common ground does the film identify? What ideas or capacities are positioned as objectivities or exteriorities that we can assume in our being towards the unknowable other and the unknowable future? 
Into Eternity propels us to consider what we might share with beings yet to come, or those long gone, and requires fundamentally that we situate ourselves first and foremost. The questions emerging from the film resound with the critique of humanism that has emerged under the designation post-humanism. This stipulates that the human is just one amongst many biological organisms and other forms of non-organic occurrences (Badmington 2003; Barad 2003; Braidotti 2006; Haraway 2008; Hayles 1999). Essentially, post-humanism seeks to shake the foundation of what it means to be human and to challenge its centrality in the world.

Since the middle of the twentieth century, critical thought has worked to decentre the human subject from the privileged position that it occupied within Enlightenment humanism: a position above and beyond the rest of the world. Within this privileged position the human mind had stood detached from the world around it; soaring above the particular historical, embodied and material circumstances it found itself in, taking the 'view from nowhere' (Haraway 1988, 589). Quite rightly, this has been challenged and post-Enlightenment thought has emphasised the manner in which human beings do not prefigure the world but rather emerge out of the forces and relations that precede it.

Post-human critiques have emerged in part from a poststructuralist concern with the problems of phenomenology, of the subject and of presence (Derrida 1982; Foucault 2002, 2005). This has led to a focus on the relationship between the human and the non-human, arguing for a concept of agency as emergent through the relationships that constitute these hybrid collectives (Gell 1998; Latour 1999, 2005), seeking to deconstruct the ontological divide between these categories (Calarco 2008; Derrida 2008; Haraway 1991, 2008). Some have turned their attention to the demands of objects (Lingis 1998; Wylie 2007), the complicity of things (e.g. Olsen et al. 2012; Pétursdóttir 2014), the independence of objects (Harman 2016), and it is increasingly common to discuss a 'return to the material' as a critique of social constructionism and the primacy of meaning (Ahmed 2008; van der Tuin 2008; Webmoor 2007). 
Post-human approaches are diverse and can be difficult, if not impossible, to align under one uniform agenda. Some theorists go as far as effectively evacuating the human from the world, or leave it as an abstraction amidst technology and disembodied language (Brooke 2000; Cecchetto 2011), even arguing that the 'posthuman view privileges informational pattern over material instantiation, so that embodiment in a biological substrate is seen as an accident of history rather than an inevitability of life' (Hayles 1999, 2). Moreover, Harman discusses situations in which humans are placed outside of influence and lose their agency, where they are not the 'active ones'. Here, they are drawn into the 'molten inner core of objects as the place where reality unfolds' (Harman 2010, 133). The post-human turn has also been accompanied by questions of materiality, and specifically, of matter as being constitutive of the social (Bennett 2010; Latour 2005; Olsen 2003). This has often been posited as a response to poststructuralist concerns with language and with text, and with social constructionist approaches that are seen to 'disembody' the social (but see Ahmed 2008, for a critique of this). This new materialism is also associated with a converging of critical theory with work in artificial intelligence, in complexity theory, in science and technology studies, in cognitive science and in neuroscience (DeLanda 2002; Parisi 2013).

New materialist critiques thus question the 'givenness of the differential categories of "human" and "non-human"” (Barad 2003, 808). The destabilisation of the privileged position of the human as distinct from other forms of existence also implies that the concept of a unified humanity, based on a universal 'human nature' cannot be maintained (Roden 2010, 29). The human here does not occupy an ontological position as separate from other classes of being, but is thrown into a world of individual co-existences, or into a 'flat ontology' (DeLanda 2002, 58) of changeable, undetermined, heterogeneous relations. Thus the human is dislocated in two ways: firstly, as no longer 'special', but just another class of being in a world 'alive' with materials, and secondly, being human does not imply belonging to an ontological category where certain traits are automatically shared with 
other phenomena of the same category. When the human is just one entity among other entities it implies that not only is the human position in the world changed in comparison with the humanist worldview, but so is the status of all other things. Hence, decentring the human is a means to appreciate the non-human.

As such, the new materialism that is integral to some articulations of post-humanism does not subscribe to older approaches to the material as a mute, passive fact that can be seen as representative of human thoughts or conditions of human life (Barad 2003, 821; see also Armstrong 1971; Gell 1998; Gosden 2005; Miller 1987). Indeed, the new materialism goes a step further and sees matter as self-differing, affective and affected (Coole and Frost 2010, 6-7). Jane Bennett, drawing on Gilles Deleuze, thus argues for a notion of a 'material vibrancy' that will help save materiality from being seen as 'passive, mechanistic, or a divinely infused substance' (Bennett 2010, xiii). Matter is instead itself vibrant and affective, and for Bennett, affect is to be equated with materiality, and is not a force attributed to or animating the material from the outside. New materialism pursues a dimension of matter that lies beyond its merely positive properties and its causal effects. The vibrancy and affectiveness of matter thus highlights a traffic between entities in the flat ontology of post-humanism without necessarily departing from, revolving around or arriving at the human. Things are, instead, independently affective and impulsive (Barad 2003, 826-827; Bennett 2010, 2; also Witmore 2014a).

To some, this may sound like a new phraseology for a fetishist reading of the material and the non-human (Ahmed 2008, 35). Yet, unlike notions of the fetish that hinge on the power of a thing to affect a human subject (Pietz 1985, 1987, 1988; Spyer 1998), post-human perspectives and new materialism seek to disentangle the human gaze. The vibrancy of matter is not just for the human, but also works independently of humans (Barad 2003, 810, 821 note 9). It is thus not centred on its social power, where the social is considered purely in terms of human communities (cf. Latour 2005), but 
is rather a question of entangled and undetermined assemblages of matter without a predetermined perspective from which relations are understood (Bennett 2010, 21-24; Harris 2014; Sørensen 2013; Webmoor and Witmore 2008).

\section{A return to the human}

Without wishing to return to a world where the human was straightforward and easily identifiable, or one in which either humans, or at least human Being, occupied a privileged ontological position, we suggest that there are a number of potential difficulties with the manner in which recent post-human critique has taken discussions forward. Fundamentally, the argument that all humans emerge solely from the mutable relations that constitute them in the present tends towards a view that posits human beings and the collectives they form (whether we term these societies, cultures, assemblages, networks, entanglements or whatever) in terms of total historical specificity and contingency, or a reductionism akin to Graham Harman's notions of undermining/overmining (Harman 2011; cf. Fowler and Harris 2015). This can make comparison across times, spaces or cultures problematic, because each human being exists only in the moment of its historical production, precluding any possibility of generalisation, including the temporal constitution of human life worlds, or, in other words, the traces that render us in relation with other times and places at any given moment. We cannot, within this formulation at least, seek any kind of common criteria for what it means to be human.

Such a proposition is aimed at eliminating essentialist claims over nature, the body, gender and so on, but has the consequence for rendering any attempts to compare the different possibilities for being human null and void (Harris and Robb 2012). It fails to find a ground for shared understandings of both different lifeways in the present and historical difference and change. Taken 
literally, this would mean that any attempt to communicate the lethal hazards of radioactive materials across the vastness of time at a site like ONKALO would be doomed to failure.

Whilst we accept the importance of these displacements as a starting point, we are concerned to maintain a space for the human within the social sciences and the humanities. We are aware that the scholars and writings touched on above belong to, or derive from, different positions, yet we identify a fundamental overlap between them (the decentring of the human), which forces us to scrutinise the question at the heart of this article: what becomes of the human in light of posthumanism?

The troubling nature of this decentred human has led some authors to argue for a return to humanism, such as the geographer Kirsten Simonsen. Simonsen $(2013,10-12)$ traces some of the histories of theoretical thought in geography, and particularly the increasing concern first with the decentred subject, then more latterly with alternative ontologies within post-humanism. She recognises the gains that have come with the growth of non-representational and more-than-human geographies, but raises a critical concern that closely parallels our central question. What, Simonsen $(2013,11)$ wonders, is 'the fate of the human in human geography'? She argues that issues of lived experience, subjectivity and agency, responsibility and politics are all missing from post-humanist approaches. To counter this she offers a reappraisal of the phenomenology of Maurice Merleau-Ponty in the light of post-humanism (cf. Coole 2007). This allows her to posit an analysis of bodily encounters, experience, emotion and agency that is non-dichotomous, generative and avoids the traps of rationalism and autonomy that have typically plagued humanist accounts (Simonsen 2013, 23).

Like Simonsen, we have concerns about the place of the human after post-humanism. Indeed, like her, we seek to think through affective, embodied and felt encounters with the world that allow us to consider what is shared. However, there are ways in which our approach differs profoundly from hers. First, despite the move Simonsen makes away from traditional humanism, the 
human remains not just a site of interest, but fundamentally central to her investigation. The body, whilst encountering and enfolding the world around it, is the primary source of interest. The rest of the world, its material qualities and engagements, the enfolding flesh of the non-human, remains secondary. Secondly, we take an alternative approach because of the differing nature of our central concern. Simonsen is interested in the way in which a new humanism can make space in the present for the encounters of bodies, agencies and political questions that she encounters in her empirical work.

Driven by our concerns with the archaeology of past and future we, however, engage with a different question, that of the extended temporality of a human-like space, and its constitution through various material worlds in the anticipated but still distant future (and by implication the distant past). Thus we require an approach that allows for the human as an experiencing, sensing, feeling body but nevertheless situates that body in a wider ecology of machines, technicity and nonhuman environments that enables a more truly material understanding of the human. In the next section we return to Into Eternity to explore why such an approach is so important, and to open up space to identify the theoretical tools required to engage with these issues.

\section{Into Eternity and the problem of the human}

Thinking through shared encounters with the material world is a fundamentally archaeological mode of thought, and our engagement with the represented space of ONKALO in Into Eternity is one that allows precisely this form of exploration. Archaeology is typically understood as a methodology, a means of peeling back layers to explore the distant past through the remnants of architecture and materiality. Archaeology, however, is a discipline of things (Olsen et al. 2012) that has chosen to deliberately and increasingly focus on thing-worlds that include, constitute and were constituted by the absent figure of the human. Whilst much archaeology has continued to presume this space of the 
human is largely filled by the autonomous and rational agent we are familiar with from humanist discourses of other social sciences, there is an increasing trend towards a more critical engagement with a range of post-humanist thinkers (e.g. Fowler 2013; Fredengren 2014; Harris 2016b; Normark 2010; Sørensen 2013; Witmore 2014a).

Basing ourselves in an archaeological mode of thinking forces us to confront both what is different about the past and the future, but also fundamentally what is shared, because if nothing can be held in common between past, present and future, then there can be no possibility for understanding worlds other than our own (Robb and Harris 2013). So how can we approach what is shared without simply summoning back the transcendent figure of the humanist subject, or emphasising the primacy of human experience?

Our consideration of Into Eternity creates a different space for thinking through the question of these shared capacities. Rather than focusing on the construction of subjectivity, a shared human nature, or a universal and individualised personhood, we can instead examined the way in which material realities and affective engagements open up new (speculative) possibilities for exploring the shared spaces occupied by humans in the present and future. Archaeologies of the future are well positioned to respond to these concerns by forcing us to engage with the complexities of material engagements, and the differences and distances that bridge disparate temporalities. As we will see, the questions posed by Into Eternity call us to attend to these archaeologies that anticipate the future, and to identify the spaces any notion of the human will have to fill. These questions might be addressed in terms of 'heritage' (e.g. Holtorf and Högberg 2014), but we prefer to take a step back from such anthropocentric frameworks and ask what becomes of the human across the vast time-scale and potentially human-less future of our nuclear legacy, a future where the material traces at stake are highly destructively in their affective capacities 
One section of the film explores attempts by previous planners of nuclear waste sites to communicate across millennia through the construction of affective landscapes. In the design principles for the projected, but never completed, Waste Isolation Pilot Plant in New Mexico (WIPP), it was stipulated that an affective agent was necessary as an alternative to words and signs, since formal communication may not be recognised in the far future (Brill 1993; Trauth et al. 1993). Instead, it was suggested that the need to avoid the nuclear repository should emerge from the 'rubble landscape', the 'landscape of thorns', the 'forbidding blocks', the 'menacing earthworks', the 'spikes bursting through grid' and the 'black hole' .

\footnotetext{
$* * *$ Figure 1 around here***
}

In the blueprints for communication across distant time lies a commitment to the capacities of future bodies to respond to these landscapes, to be involved in the coproduction of affective spaces that then move bodies in particular ways. There is a sense in these attempts of a common response to spaces as forbidding, or frightening, a common sensitivity to atmosphere that could outlive language and civilisation, a commitment to our enduring capacities to respond to materially produced atmosphere in a somehow predictable way. More than a 'semiotics of fear' (Kuletz 1998, 288), these spaces would act as an affective deterrent against future investigations of the site. They would 'attempt to give you a feeling rather than give you a detailed message. Intuitively, you would expect people to react to something frightening. Better than to a detailed message' (Interviewee, Into Eternity). As such, the film raises the question of how certain kinds of affective experience may better bridge the gaps between present and future than any message located solely in language. In the blueprints for communication across distant time described in the film lies a commitment to the affective capacities of future bodies to respond to the landscapes, to be involved in the coproduction of affective spaces 
that then move bodies in particular ways. There is a sense in these attempts of a common response to spaces as forbidding, or frightening, a common sensitivity to our surroundings that could outlive language and civilisation, a commitment to our enduring capacities to respond to materially produced atmosphere in a somehow predictable way. Here, the desire to communicate across millennia emphasises a putative common vulnerability, rooted in a shared fear and anxiety towards pain and death. Into Eternity draws upon these shared capacities to communicate with a putative future audience and assumes a fear or anxiety towards pain and death which is irrespective of time and space. The film begins with a warning:

We have taken great pain to be sure that you are protected.

This is not a place for you to live in. You should stay away from this place and then you will be safe.

This is not a place of honour. No esteemed dates are commemorated here. You should not have come here [this is] dangerous and repulsive. There is nothing here for you. Go no further.

$* * *$ Figure 2 around here***

The act of warning points to assumptions about the universality of fear of pain and death, of an attitude towards the preservation of life which is presented as unquestioned and unquestionable, as outside of historical contingency. The vulnerability of the human body is held as central to the concerns of those managing the facility, not just now, but in the distant future. Judith Butler's (2006, $44 ; 2009)$ work on war and representation makes a crucial distinction between 'precariousness' as an ontological assumption of shared human vulnerability, which she suggests could constitute the basis for a new politics, and precarity, which is the differential distribution of vulnerability due to the 
different normative framings of bodies. With regard to her concept of precariousness, she argues that 'lives are by definition precarious: they can be expunged at will or by accident; their persistence is in no sense guaranteed. In some sense this is a feature of all life' (Butler 2009, 25). This shared vulnerability and dependence, as an ontological category and political foundation, is central to the relations between present and future in Into Eternity. The affective opening that this creates joins people together, and can speak over countless millennia. While vulnerability is of course a differently shared capacity, it is precisely this intersubjective situatedness that offers the possibility for sharing the experience of fragility and vulnerability (Simonsen 2013, 18), and we contend that this intersubjectivity is the ground for sharing across vast temporal horizons and beyond culturally recognisable contexts.

At ONKALO, it is assumed that the inhabitants of the future move and feel. It is assumed that they coexist and live and die. While evidence suggests that the desire to avoid death and pain is by no means universal, there are material realities to both death and pain that are shared regardless of how they are perceived (Robb and Harris 2013). This reveals precisely where we can connect across millennia with humans in both the past and the future (DeSilvey 2012, 35). It is not attitudes towards death and pain that have or will remain stable (they are not even stable across a single country in the world today), rather it is their reality as existential challenges that cannot be escaped. Bodies are vulnerable, humans are vulnerable, and often, as Martin Heidegger (1962, 250-251) noted, this beingtowards-death and our knowledge of it is the source of anxiety. At ONKALO the threat of radiation as an initially undetectable but nevertheless highly affective force is revealed in the warning at the beginning of the film, as narrated by the director: 'Something is happening to your body right now. You cannot feel it with your senses'. The effects of the radiation produced by isotopes, such as Plutonium-239, Cesium-135, Iodine-129 and Uranium-238, will become apparent, and the human body, unless protected by materials that can absorb the damage, remains vulnerable to it. Across the 
millennia, then, from past to future, the affective qualities of pain and death create space for a notion of a humanness that is shared, implying that a 'future society deserves to have the facts it needs to protect itself from our waste' (Lomberg and Hora 1997, 175). In fact the first line of protection comes from the materials employed and their own affective properties, from the way iron and copper contain the fuel, to the fact that bentonite clay will expand if it comes into contact with water, making it less likely that this latter substance can penetrate the repository and carry away dangerous material with it. In the absence of human knowledge and interference the materials continue to affect each other, deep within ONKALO.

\footnotetext{
$* * *$ Figure 3 around here***
}

The second shared capacity assumed in Into Eternity is a notion of care towards the Other. The very construction of ONKALO is presented as evidence of this concern, the need to manage things that are perceived as dangerous both in the present and into the future. Specifically, since the potential future visitor or explorer at ONKALO is unknown, communication is not projected uniquely towards a human visitor, and the nature, character and form of a future intruder remains an openended question. More precisely, the great unknown for the ONKALO developers is language, and whether future beings will have any chance of recognising the warnings against the lethal contents of the site. One of the developers interviewed in the film argues that we can assume a number of basic traits about the future visitors, and suggests that they will be able to recognise the danger of the site by being able to measure dangerous components. The interviewer asks how he can know if they will think about this danger, to which the developer answers with the confident assumption that if they have the ability to drill into the facility, they will have the technology to detect danger. 
Knowledge and communication thus form a nexus in the imagination of future intruders into waste repositories: should they succeed in intruding, then they will also necessarily possess a certain knowledge, and thus will also be able to understand crucial parts of the communication from 21 st century humans. The worry, however, remains that this may not be sufficient and language and communication with the unknown Other nevertheless remains a problem. The ONKALO developers seek to devise a number of 'markers' that will be intelligible to a future visitor independent of language skills and particular cultural codes. In essence it needs to be an 'anti-code' (Lomberg and Hora 1997, 176). In both ONKALO and the planned affective landscapes at WIPP, central questions are raised about the place of the human, and what it is about the human that endures and that we hold in common.

By thinking through the issues that an anticipatory archaeology of the future at ONKALO raises in Into Eternity, and about the affective capacities of radioactive materials, a conceptual space is opened. This space is shaped by this consideration of shared vulnerability, materiality and affect, and emphasises the place of the human as a shared set of processes, potentials and 'existential challenges' set within a limited, but not fixed or bounded, material entity. Here we see the outline of a shared humanity not rooted in enlightenment assumptions, or the figure of 'Man'. Through an engagement centred on the concerns of archaeology to conceptualise such a shared humanity, ONKALO opens new areas for analysis for us, and helps us to concentrate on ways of thinking through the problems we have identified in this article. In particular we argue that it is in a reconsideration of the relations between affect and materiality that we can engage with what is shared in the past, present and the future - and it is this we term the materially-affective. Our engagement with ONKALO shows that it is in precisely this area that we can identify and analyse the potential for shared being, and shared vulnerability. 
$* * *$ Figure 4 around here***

The concept of the materially-affective recognises that all materials are potentially affective. Inspired by the philosophy of Baruch Spinoza, Gilles Deleuze and new Spinozist materialist thinkers coming from non-representational theory in geography, cultural theory and post-phenomenology, we suggest that an approach to materials that reveals their capacity to be affective, to generate affects and be transformed by them in turn, offers us a new way to engage with shared elements of human geographies (spatial, mnemonic, emotional, social, material) through time. Thus, being human involves the exploration and experience of similar materially-affective processes: of gendered experience, eating, sleeping, having sex, dying and dealing with death, of anxiety and of shared vulnerability, even if these things themselves are only ever constituted in a manner thoroughly and inextricably intermingled with the specificities of their world (Harris and Robb 2012; Robb and Harris 2013).

This materially-affective anticipatory archaeology emphasises sites, as opposed to people, or groups. It offers a perspective where materials have histories, where they move and feel through each other. Copper, iron, bentonite clay, gneiss bedrock and ceramic fuel rods affect each other, allowing certain forms of change and transformation and delaying others, their own histories and properties producing their own vibrant and affective encounters. Within this perspective, humans are another material body. These materially-affective engagements can then open up the possibility for communication with our putative descendants at ONKALO and at other future archaeological sites. The materially-affective will take place without human participation, without our intervention or intention, and outside of our knowledge.

***Figure 5 around here*** 


\section{Affect and atmosphere}

We do not see the argument we are putting forward here as a rejection of post-humanism or new materialism; we are not attempting to coin some new turn, revert to humanism or embrace Christianstyle languages of transcendence. Our central contention is that an approach that emphasises the role of the materially-affective has the capacity to create space for the shared histories and futures that link human beings across contexts, not as human individuals but rather as sites of possibilities. In this section, we explore two approaches central to our project. We begin by fleshing out the ontological affectivity of materials, through Spinoza's Ethics (Spinoza 1996) and then move on to consider how Peter Sloterdijk's concept of atmosphere, in conjunction with the concept of affect, can contribute to these debates.

In part one of the Ethics, Spinoza sets out a radical monism that sees both ideas and matter as different attributes of the same indivisible 'Substance'. All objects and bodies are modes of the totality of Substance. Considering individual bodies as modes of Substance can lead to a radical rethinking of the bounded nature of things and bodies: it enables a relational ontology, where individuals are perceived as part of a totality (Nature), and as such precludes any dualistic thinking about, for example, nature and culture, or individual and society, or human and non-human, since all are simply modes of the same Substance.

Spinoza understands individual bodies as any 'more or less stable configuration' at the level of the organism, the body politic or smaller; organic or mineral (Hampshire 1951, 7). Individuals emerge from Substance as specific ratios of speed to slowness - as 'rhythm' (Spinoza 1996, 41-43); as such Spinoza's metaphysics provides a way of rethinking structures and individuals such that 'structure is rhythm' (Deleuze 1997, 24), and bodies emerge through their relation with other bodies. Deleuze makes this clear: 
if I learn to swim or dance, my movements and pauses, my speeds and slownesses, must take on a rhythm common to that of the sea or my partner, following a more or less durable adjustment (Deleuze 1997, 24).

Motion is central to Spinoza's philosophy of bodies. Material bodies are continually affected by different forces, for example, of gravity, of other bodies, of wind, of light. These 'affections' push and pull bodies, varying their ratio of speed and slowness, while the individual persists to a greater or lesser extent in its striving to exist - in its conatus (Deleuze 1988). Where these bodies impact on each other, they affect each other - they impress on, or change the state of the other (Brennan 2004; Harris 2016a). What Spinoza gives us, then, is a position from where we can consider materials as always on the move - reaching out to us and each other and calling us and them in. Affect happens when bodies impress upon each other, when they change the relation.

There can be no clinical distinction here between material and affect; this is not a new distinction between form and process, but rather a recognition that material bodies are constantly produced through affect, and generate affective relations with others. The materially-affective is a weight of effects and potentials that confronts and is confronted by the human being, and which textures and defines human life and social relations. As a consequence, the materially-affective is never static, but constantly in flux and flow, emerging and dissolving. Affective relations are transmitted (Brennan 2004), not only between human beings, but also across people, places and things (Dawney 2011a, 2011b; Harris and Sørensen 2010) and are produced by chains of events and their rupture. The field of materially-affective relations will thus always have a history, a temporal trajectory, hinging on memory and forgetting, on monumentalization and erasure, on presences and absences (Dawney 2011b, 2013). 
Materially-affective bodies feel through each other. They come together and pull apart in the making of history, individuate through this feeling-through, rub off and erode each other, shaping muscular growth, synaptic pathways and relations of production, causing pain, calm, memory. And through this affective feeling-through, comes feeling itself. To understand the world in materially-affective terms is to consider bodies as always involved in their mutual production, and how these productions are contingent and historical, and perhaps most importantly, the way in which these productive movements are felt through the bodies of both human and non-human. Into Eternity's casual moving from beast to human to tree to excavator to laboratory provides a way of thinking about these shared worlds of movement and affect - where bodies rub against one another in the making of a world.

The second conceptual frame we turn to is that of the atmosphere as an emerging product of shared life. In Sloterdijk's work, shared life is figured as a defining and productive quality of humanity:

I claim that the first common activity of humans is not hunting, not sexuality, not the raising of children, and by no means agriculture, livestock breeding, or industry, but the production of a resonance between those who live together. For present-day cultures the question of survival has become a question of the way in which they are reproduced as atmospheric communities. Even physical atmospheres have passed to the stage of their technical producibility. The future era will be climate-technical, and as such technologically oriented. It will be increasingly seen that societies are artificial from the ground up. The air that, together and separately, we breathe can no longer be presupposed. Everything must be produced technically, and the metaphorical atmosphere as much as the physical atmosphere (Sloterdijk 2011a, 245). 
In line with Sloterdijk's analysis, we argue that the concept of the materially-affective, and the notion that humans are both materially affective and materially affected, enables an appreciation of what humans have in common without lurching back to a universal subject/body. Thus, we argue that the human is not characterised by the body or by a transcendental form of subjectivity, but by the shared potentials of materially-affective embodied subjectivities and the atmospheres they are involved in producing, and hence material as well as immaterial, human as well as non-human, communities or 'spheres'. Sloterdijk argues that a fundamental condition for the human is 'being-in-spheres' (Sloterdijk 2011b, 45-46), 'equivalent to the Dasein of a constantly spreading and unpredictably drifting architectural rhizome' (Sloterdijk 2007, 138). This implies, as Sloterdijk puts it, that 'existence includes the presence of a pre-objective something floating around me' (Sloterdijk 2011b, 478), and hence that subjectivity is always animated by something more than the subject itself.

While spheres imply the sharing of infrastructure, air, ideas, meaning and so forth, they are also fragile, susceptible to reconfigurations, bursts, and mergers with other spheres (Sloterdijk 2011b, 48), illustrated by the metaphor of the sphere in the form of bubbles, globes, and foam. The future need for producing atmospheres, addressed by Sloterdijk above, can, as Gernot Böhme (2013) argues in another context, seem paradoxical or even perverse, in the light of the commonplace expectations of atmosphere to offer a sense of perceived authenticity or genuine experience, as somehow existing prior to or independent of human manipulation - as something that simply emerges. Yet at the same time, atmosphere is also deeply related to a human sense of presence and activity, including anticipation, affective response and corporeal intervention, rather than the mere passive reception of a place or an event. In this sense, atmosphere revolves around a simultaneous production and presence of people and places (Bille et al. 2015; Bille and Sørensen 2016; Sørensen 2015). 


\section{Sharing differences}

This discussion of the material nature of affect and atmosphere sets the scene for a re-emergence of the human as a site of possibilities. Here we position a world and mode of analysis based on materials and atmospheres, both human and non-human, and we consider how our material legacy is a result of our mutual entanglement in the world of technology, geology, life and time. To this end, the social is considered, as Anderson and Wylie (2009) assert, in terms of those material assemblages that humans are embroiled within, yet which also operate above, below and alongside the human as organism. Thus the social consists of 'the nervous system, hormones, hands, love letters, screens, crowds, money' (Anderson and Harrison 2006, 334). We are interested in the interface between humans and those letters and screens, and the affects that surface as a result. The affective landscapes left for future archaeologists can thus be considered in terms of encounters between materialities and atmospheres, where, as social scientists, we are especially interested in those which are human in form, or connected to humans.

Yet it remains the case that we have not yet identified anything specifically human from this embroiled assemblage of materially-affective bodies. All the bodies that make it up - and the sites of possibility these bodies mark - are so far undifferentiated. Yet a human is different from a microbe, and both are different from a dinosaur or a black hole. The question is how. What is it about the human that is different? We therefore want to understand how different kinds of humanity can emerge from a radically immanent field of affective relations, sharing certain properties but not others.

To think about this further consider also the materially-affective potentials of clay that emerge in conjunction with human beings, not present when the clay is alone. It can be shaped and fired into new forms, it can carry substances within these things, move and mix with other elements, and fracture and fragment and carry meaning. In the context of ONKALO it can seal off canisters and 
prevent water accessing the rods to carry off the dangerous isotopes. Thus, materials emerge through their 'capacities' (DeLanda 2006, 10) as more diverse and complex in their affective conjunctions with people, just as people become more complex and diverse in the affective engagements they share with the world around them. By stating our interest is in the human, we do so because of the complexity of their emerging assemblage with things, places and other non-humans (also Bille and Sørensen 2016).

Identifying the difference between humans, microbes, dinosaurs and black holes is, of course, relatively uncontroversial. Yet the reverse of this is far more contentious: if all human beings are different from microbes, are they different in (some) similar ways? Does any attempt to access what is shared between human beings merely return us to a position that posits a universal and a historical nature/material/biology? Given the specificity of bodies produced through their historical becoming, what tools can we use to think about the relations between people and things, the affects and atmospheres they produce, that exist across time and space?

To answer these questions so we need to think about the way materially-affective forms of being reoccur because of humanity's shared history. This history is always both biological and cultural (indeed neither can precede the other) and traverses, yet it is also sustained within, time (Robb and Harris 2013; c.f. Witmore 2012; Witmore 2014b). The real differences that exist in the shared capacities of humanity are of vital importance, but they should not disguise the fact that even in their variation, these materially-affective forms of being link us through time and across space. Just as a concentration on the materially-affective allows us to differentiate humans from non-humans in terms of their relational entanglements, without a plea to universal personhood or subjectivity, so it allows us to recognise shared categories of experience without returning to a universal natural body, or denying historical specificity. It is these shared, materially-affective capacities, alongside the temporal transformation of our evidence, that allow our archaeological lens to explore humanity's 
past through the materials they interacted with over hundreds of thousands of years, and to cast our glance into the future to think about how a site like ONKALO can make sense across such a vast temporal prospect.

\section{Conclusion: Archaeologies of the future}

Complementing the beautiful, haunting and grand camera gestures, Into Eternity cuts to intimate, close-up shots of workers getting changed, eating in a portakabin, sleeping in contractors' accommodation, drawing our attention to the details of lives lived. The camera focuses on the small details, on the way a shirt has been thrown over the overhead light to make the room feel cosier, and on a worker looking at the clock while eating lunch in a portakabin. This worker, whose name is only mentioned at the very end in the credits (unlike the interviewees, whose names appear on screen), seems to embody the figure of the human - a body that works, seeks comfort, sleeps and eats. The nameless worker does not speak - his position in the film is a body amongst bodies. The camera moves from outside in the forest where elk are standing in a clearing, startled by a blast from the ONKALO site, into the workers' rest room. There, the camera pans past a notice board with a diagram of the tunnels, various notices, a clock and a topless pin-up. At the table, the unnamed worker looks at his watch, resting, in his hi-visibility jacket. The worker represents human needs: eating, sex, sleeping and working. He becomes a figure for the human, for the bodies of today's people. In another scene, amidst vast drilling and earth moving machines, the camera focuses on one tunnel worker wiping something from the other worker's eye - two men in hard hats and ear defenders. Corporeal vulnerability and interdependence and care for the other: the workers embodying those points of connection that we seek across millennia.

$* * *$ Figure 6 around here*** 
The filmic landscapes of Into Eternity, we argue, represent a mode of understanding the world which is fundamentally archaeological. It is concerned with things and spaces and bodies, and the worlds that emerge from these entanglements. It is concerned with thinking about the material articulations of care for the other, and of a shared vulnerability that attempts to speak across millennia, and with the properties of rock, metal and bodies that are involved in these attempts. It provides an opportunity to explore how a materially-affective gaze can support the production of an imaginative and anticipatory temporal commons. This involves projecting a view of ourselves and our own means of communication into a distant, potentially non-human Other, which looks back on us through our material traces. Through thinking archaeologically about bodies among bodies, about the production of materially-affective atmospheres, we can attempt to think across millennia, to think about our worlds and future worlds as entanglements of technologies and bodies, of affects and atmospheres within which we can attempt to gain points of purchase through that which may be shared, or held in common.

In this article we have posited that the role and position of the 'human' (including its occasionally exceptional or central position) cannot straightforwardly be discarded. Our explorations and thought exercises with Into Eternity have allowed us to explore how the affective capacities of bodies can provide a set of theoretical tools through which we can develop lines of attachment - lines through which we can consider and highlight what we hold in common. While these lines are of course speculative, they do offer a means of looking beyond a world of contingency, in order to reinstate a sense of what is shared, and what is held in common in order to focus on the site of the human in the human sciences. By definition this is an indeterminate sharing. It does not serve to divide through the construction of semantic boundaries between human and non-human. It is a 
delicate exploration into what we can take away from various critiques of the human in order to allow for the human to re-emerge.

To explore what is shared across timespaces has implications for philosophy, archaeology, anthropology and all the social sciences. Normally we are led back to the question of knowing the Other, and the problems of articulating this otherness. Here, we have turned around the question to instead explore whether it is possible to consider what is shared in terms of points of connection and lines of attachment, rather than divergence, disconnection and disarticulation. While the post-human critique has necessarily decentred and de-essentialized the site of the human, it is now time to consider the form in which it may re-emerge, suitably humbled, but nevertheless as that which interests and engages us as researcher in the humanities or as social scientists.

Through this, we have argued for a move away from pure specificity and contingency, towards a seeking out of things that are held in common, points upon which we can gain some sort of purchase; a position from which to enquire. Each of these modes of shared existence are spaces and possibilities created by the materially-affective nature of human being. Thinking through these temporal commons can thus contribute in turn to efforts by the designers of ONKALO and other sites to imagine or anticipate the human-yet-to-come. It further enhances the emphasis on the shared nature of the materially-affective that prefigures any construction of the human, refusing the centrality of the human yet acknowledging the vulnerability and care that we have argued are central to the human's affective materiality.

In this article we have employed an anticipatory archaeology to argue that some of the most effective tools for thinking about the human after the critique of humanism lay within that very critique itself: the focus on material relations, the emphasis on affect, the positioning of a world of relation and without centre. Post-humanist critiques, and the legacy of Spinoza's philosophy in terms of the concept of affect and the way in which it has contributed to the 'new materialisms', have been 
central to this carving out a space for the human after post-humanism. In this light, post-humanism has not so much turned its back on the human as it has allowed for a new and different, possibly more inclusive, consideration of what it means to be human. With this point of departure, we can start to move towards a human science that searches for these points of similarity, these positions from which to identify what is shared, and in doing so, move towards a repositioning of the human as a point of interest; a place which we, unashamedly, state is important, because it is a name that we give to a set of material capacities and vulnerabilities that we share with others.

\section{Acknowledgements}

This paper began life as a presentation at TAG in 2010 in Dan Hicks' session Manifestos for Materials. We would like to thank Dan and everyone present there for helping us kick off the train of thought that has transformed our manifesto into this publication. The paper has benefited from the comments of two annonymous peer reviewers and a thoughtful interrogation by Póra Pétursdóttir. We are also indebted to Sue Weidemann and Michael Madsen for permitting the use of images for, respectively, the work for WIPP and Into Eternity. Any errors we have failed to anticipate remain very much our own.

\section{References}

Ahmed, Sara. 2008. "Some Preliminary Remarks on the Founding Gestures of the 'New Materialism'." European Journal of Women's Studies no. 15 (1):23-39.

Anderson, B., and J. Wylie. 2009. "On Geography and Materiality." Environment and Planning A: Urban and Regional Research no. 41 (2):318-335.

Anderson, Ben, and Paul Harrison. 2006. "Questioning affect and emotion." Area no. 38 (3):333-335. 
Armstrong, Robert Plant. 1971. The Affecting Presence: An Essay in Humanistic Anthropology. Urbana, Ill.: University of Illinois Press.

Badmington, Neil. 2003. "Theorizing Posthumanism." Cultural Critique no. 53 (Winter):10-27.

Barad, Karen. 2003. "Posthumanist Performativity: Toward an Understanding of How Matter Comes to Matter." Signs no. 28 (3):801-831.

Bennett, Jane. 2010. Vibrant Matter: A Political Ecology of Things. Durham, NC: Duke University Press.

Bille, Mikkel, Peter Bjerregaard, and Tim Flohr Sørensen. 2015. "Staging atmospheres: Materiality, culture, and the texture of the in-between." Emotion, Space and Society no. 15:31-38.

Bille, Mikkel, and Tim Flohr Sørensen. 2016. "Into the Fog of Architecture." In Elements of Architecture: Assembling Archaeology, Atmosphere and the Performance of Building Space, edited by Mikkel Bille and Tim Flohr Sørensen, 1-29. London: Routledge.

Bradshaw, Peter. 2010. "Into Eternity - review." The Guardian, 12 November 2010, 8.

Braidotti, Rosi. 2006. "Posthuman, All Too Human: Towards a New Process Ontology." Theory, Culture \& Society no. 23 (7-8):197-208.

Brennan, Teresa. 2004. The Transmission of Affect. Ithaca, N.Y.: Cornell University Press.

Brill, Michael. 1991. Site Design to Mark the Dangers of Nuclear Waste for 10,000 Years. Buffalo: The Buffalo Organization for Social and Technological Innovation Inc. (BOSTI). 1993. An Architecture of Peril: Design for a Waste Isolation Pilot Plant, Carlsbad, New Mexico. http://www.arch.ksu.edu/seamon/Brill.htm. Accessed April 192012.

Brooke, Collin Gifford. 2000. "Forgetting to be (Post)Human: Media and Memory in a Kairotic Age." JAC: A Journal of Composition Theory no. 20 (4):775-795. 
Buchli, Victor, and Gavin Lucas. 2001. "The absent present: Archaeologies of the contemporary past." In Archaeologies of the Contemporary Past, edited by Victor Buchli and Gavin Lucas, 3-18. London: Routledge.

Butler, Judith. 2006. Precarious Life: The Powers of Mourning and Violence. London: Verso. 2009. "Violence, Mourning, Politics." In Emotions: A Cultural Studies Reader, edited by Jennifer Harding and E. Deidre Pribram, 387-402. London: Routledge.

Böhme, Gernot. 2013. "The art of the stage set as a paradigm for an aesthetics of atmosphere." Ambiances:http://ambiances.revues.org/315. Accessed January 22014.

Calarco, Matthew. 2008. Zoographies: The Question of the Animal from Heidegger to Derrida. New York: Columbia University Press.

Cecchetto, David. 2011. "Deconstructing Affect: Posthumanism and Mark Hansen's Media Theory." Theory, Culture \& Society no. 28 (5):3-33.

Coole, Diana H. 2007. Merleau-Ponty and Modern Politics after Anti-Humanism. Lanham, Maryland: Rowman \& Littlefield Publishers.

Coole, Diana H., and Samantha Frost. 2010. "Introducing the New Materialisms." In New Materialisms: Ontology, Agency, and Politics, edited by Diana H. Coole and Samantha Frost, 1-46. Duke University Press: Durham, NC.

Dawney, Leila Alexandra. 2011a. "The motor of being: a response to Steve Pile's 'Emotion and Affect in Recent Human Geography." Transactions of the Institute of British Geographers, New Series no. $36(4): 599-602$.

2011b. "Social Imaginaries and Therapeutic Self-work: the ethics of walking as embodied imagination." Sociological Review no. 59:535-552.

2013. "The interruption: investigating subjectivation and affect." Environment and Planning

D: Society and Space no. 31 (4):628-644. 
DeLanda, Manuel. 2002. Intensive Science and Virtual Philosophy. London: Continuum. 2006. A New Philosophy of Society: Assemblage Theory and Social Complexity. London: Continuum.

Deleuze, Gilles. 1988. Spinoza: Practical Philosophy. San Francisco: City Lights Books. . 1997. "Spinoza and the Three "Ethics"." In The New Spinoza, edited by W. Montag and T. Stolze, 21-34. Minneapolis, Mn.: University of Minnesota Press.

Derrida, Jacques. 1982. Margins of Philosophy. Translated by Alan Bass. Chicago: University of Chicago Press.

. 2008. The animal that therefore I am. New York: Fordham University Press.

DeSilvey, Caitlin. 2012. "Making sense of transience: an anticipatory history." Cultural Geographies no. 19 (1):31-54.

Foucault, Michel. 2002. The Archaeology of Knowledge. London: Routledge. Original edition, 1969.

- 2005. The Hermeneutics of the Subject: Lectures at the Collège de France, 1981-82. Translated by Graham Burchell. New York: Picador.

Fowler, Chris. 2013. Emergent Past: A Relational Realist Archaeology of Early Bronze Age Mortuary Practices. Oxford: Oxford University Press.

Fowler, Chris and Oliver J.T. Harris 2015. "Enduring Relations: Exploring a Paradox of New Materialism". Journal of Material Culture 20 (2): 127-148.

Fredengren, Christina. 2014. "Posthumanism, the transcorporeal and biomolecular archaeology." Current Swedish Archaeology no. 21:53-71.

Freud, Sigmund. 1959. "Delusions and Dreams in Jensen's Gradiva." In The Standard Edition of the Complete Psychological Works of Sigmund Freud, Volume IX, 7-93. London: The Hogarth Press and the Institute of Psychoanalysis. First published 1907.

Gell, Alfred. 1998. Art and Agency: An Anthropological Theory. Oxford: Oxford University Press. 
González-Ruibal, Alfredo. 2013. "Reclaiming archaeology." In Reclaiming Archaeology: Beyond the Tropes of Modernity, edited by Alfredo González-Ruibal, 1-29. London: Routledge.

Gosden, Chris. 2005. "What Do Objects Want?" Journal of Archaeological Method and Theory no. $12(3): 193-211$.

Graves-Brown, Paul, Rodney Harrison, and Angela Piccini. 2013. "Introduction." In The Oxford Handbook of the Archaeology of the Contemporary World, edited by Paul Graves-Brown, Rodney Harrison and Angela Piccini, 1-23. Oxford: Oxford University Press.

Hampshire, Stuart. 1951. Spinoza. Harmondsworth: Penguin.

Haraway, Donna. 1988. "Situated Knowledges: The Science Question in Feminism and the Privilege of Partial Perspective." Feminist Studies no. 14 (3):575-599.

-1991. Simians, Cyborgs, and Women: The Reinvention of Nature. London: Free Association. _. 2008. When Species Meet. Minneapolis: University of Minnesota Press.

Harman, Graham. 2010. Towards Speculative Realism: Essays and Lectures. Winchester: Zero Books.

- 2011. "On the Undermining of Objects: Grant, Bruno, and Radical Philosophy." In The Speculative Turn: Continental Materialism and Realism, edited by Levi Bryant, Nick Srnicek and Graham Harman, 21-40. Melbourne: re.press.

_. 2016. Immaterialism. Cambridge: Polity Press.

Harris, Oliver J. T. 2014. "(Re)assembling communities." Journal of Archaeological Method and Theory no. 21 (1):76-97.

. 2016a. "Affective architecture in Ardnamurchan: assemblages at three scales." In Elements of Architecture: Assembling Archaeology, Atmosphere and the Performance of Building Space, edited by Mikkel Bille and Tim Flohr Sørensen, 195-212. London: Routledge. 
2016b. "Becoming post-human: identity \& the ontological turn." In Creating Material Worlds: The uses of identity in archaeology, edited by E. Pierce, A. Russell, A. Maldonado and L. Campbell, 17-37. Oxford: Oxbow.

Harris, Oliver J. T., and John Robb. 2012. "Multiple Ontologies and the Problem of the Body in History." American Anthropologist no. 114 (4):668-679.

Harris, Oliver J. T., and Tim Flohr Sørensen. 2010. "Rethinking emotion and material culture." Archaeological Dialogues no. 17 (2):145-163.

Harrison, Rodney. 2011. "Surface assemblages: Towards an archaeology in and of the present." Archaeological Dialogues no. 18 (2):141-161.

Hayles, Katherine N. 1999. How We Became Posthuman. Chicago: University of Chicago Press.

Heidegger, Martin. 1962. Being and Time. New York: Harper and Row. First published 1927.

Holtorf, Cornelius, and Anders Högberg. 2014. "Communicating with future generations: what are the benefits of preserving for future generations? Nuclear power and beyond." European Journal of Post-Classical Archaeologies no. 4:315-330.

Kuletz, Valerie L. 1998. The Tainted Desert: Environmental Ruin in the American West. London: Routledge.

Latour, Bruno. 1999. Pandora's Hope: Essays on the Reality of Science Studies. Cambridge, Ma: Harvard University Press.

- 2005. Reassembling the Social: An Introduction to Actor-Network Theory. Oxford: Oxford University Press.

Lingis, Alphonso. 1998. The Imperative. Bloomington, IN: Indiana University Press.

Lomberg, Jon, and Stephen C. Hora. 1997. "Very Long Term Communication Intelligence: The Case of Markers for Nuclear Waste Sites." Technological Forecasting and Social Change no. $56: 171-188$. 
Miller, Daniel. 1987. Material Culture and Mass Consumption. Oxford: Blackwell.

Normark, Johan. 2010. "Involutions of Materiality: Operationalizing a Neo-materialist Perspective through the Causeways at Ichmul and Yo'okop." Journal of Archaeological Method and Theory no. 17 (2):132-173.

Olsen, Bjørnar. 2003. "Material Culture after Text: Re-Membering Things." Norwegian Archaeological Review no. 36 (2):87-104.

Olsen, Bjørnar, Michael Shanks, Timothy Webmoor, and Christopher Witmore, L. 2012. Archaeology: The Discipline of Things. Berkeley: University of California Press.

Parisi, Luciana. 2013. Contagious Architecture. Computation, Aesthetics and Space. Cambridge, MA: MIT Press.

Pétursdóttir, Póra. 2014. "Things out-of-hand: the aesthetics of abandonment." In Ruin Memories: Materialities, Aesthetics and the Archaeology of the Recent Past, edited by Bjørnar Olsen and Thóra Pétursdóttir, 335-363. London: Routledge.

Pietz, William. 1985. "The Problem of the Fetish I." RES: Journal of Anthropology and Aesthetics no. 9:5-17.

1987. "The Problem of the Fetish II: The Origin of the Fetish." RES: Journal of Anthropology and Aesthetics no. 13:23-45.

- 1988. "The Problem of the Fetish III: Bosman's Guinea and the Enlightenment Theory of Fetishism." RES: Journal of Anthropology and Aesthetics no. 16:105-123.

Robb, John, and Oliver J. T. Harris. 2013. The Body in History: Europe from the Paleolithic to the Future. Cambridge: Cambridge University Press.

Roden, David. 2010. "Deconstruction and Excision in Philosophical Posthumanism." Journal of Evolution and Technology no. 21 (1):27-36. 
Simonsen, Kirsten. 2013. "In Quest of a New Humanism: Embodiment, experience and phenomenology as critical geography." Progress in Human Geography no. 37 (1):10-26.

Sloterdijk, Peter. 2007. "Foam City." Log no. 9 (Winter/Spring):63-76.

2011a. Neither Sun nor Death. Los Angeles: Semiotext(e).

2011b. Bubbles: Spheres Volume 1 - Microspherology. Cambridge, MA: MIT Press. Original edition, 1998.

Spinoza, Baruch. 1996. Ethics. Translated by Edwin Curley. London: Penguin. Original edition, 1677.

Spyer, Patricia. 1998. Border Fetishisms: Material Objects in Unstable Spaces. London: Routledge.

Sørensen, Tim Flohr. 2013. "We Have Never Been Latourian: Archaeological ethics and the posthuman condition." Norwegian Archaeological Review no. 46 (1):1-18.

—. 2015. "More Than a Feeling: Towards an archaeology of atmosphere." Emotion, Space and Society no. 15:64-73.

Trauth, Kathleen M., Stephen C. Hora, and Robert V. Guzowski. 1993. Expert Judgment on Markers to Deter Inadvertent Human Intrusion into the Waste Isolation Pilot Plant. Sandia Report SAND92-1382, UC-721. Albuquerque, NM: Sandia National Laboratories, United States Department of Energy.

van der Tuin, Iris. 2008. "Deflationary Logic: Response to Sara Ahmed's 'Imaginary Prohibitions: Some Preliminary Remarks on the Founding Gestures of the "New Materialism." European Journal of Women's Studies no. 15 (4):411-416.

Webmoor, Timothy. 2007. "What about 'one more turn after the social' in archaeological reasoning? Taking things seriously." World Archaeology no. 39 (4):563-578. 
Webmoor, Timothy, and Christopher L. Witmore. 2008. "Things Are Us! A Commentary on Human/Things Relations under the Banner of a 'Social Archaeology'." Norwegian Archaeological Review no. 41 (1):53-70.

Witmore, Christopher, L. 2012. "The Realities of the Past: Archaeology, Object-Orientations, Pragmatology." In Modern Materials: Proceedings from the Contemporary and Historical Archaeology in Theory Conference 2009, edited by Brent Fortenberry and Laura McAtackney, 25-36. Oxford: Archaeopress.

_ 2014a. "Archaeology and the New Materialisms." Journal of Contemporary Archaeology no. 1 (2):203-224.

—. 2014b. "Chronopolitics and Archaeology." In The Encyclopedia of Global Archaeology, edited by Claire Smith, 1471-1476. New York: Springer.

Wylie, John. 2007. "The spectral geographies of W.G. Sebald." Cultural Geographies no. 14 (2):171188.

\section{Filmography}

Kubrick, Stanley. 1968. 2001: A Space Odyssey. Metro-Goldwyn-Mayer

Tarkovsky, Andrey. 1979. Stalker. Mosfilm

Madsen, Michael. 2010. Into Eternity. Magic Hours Films 


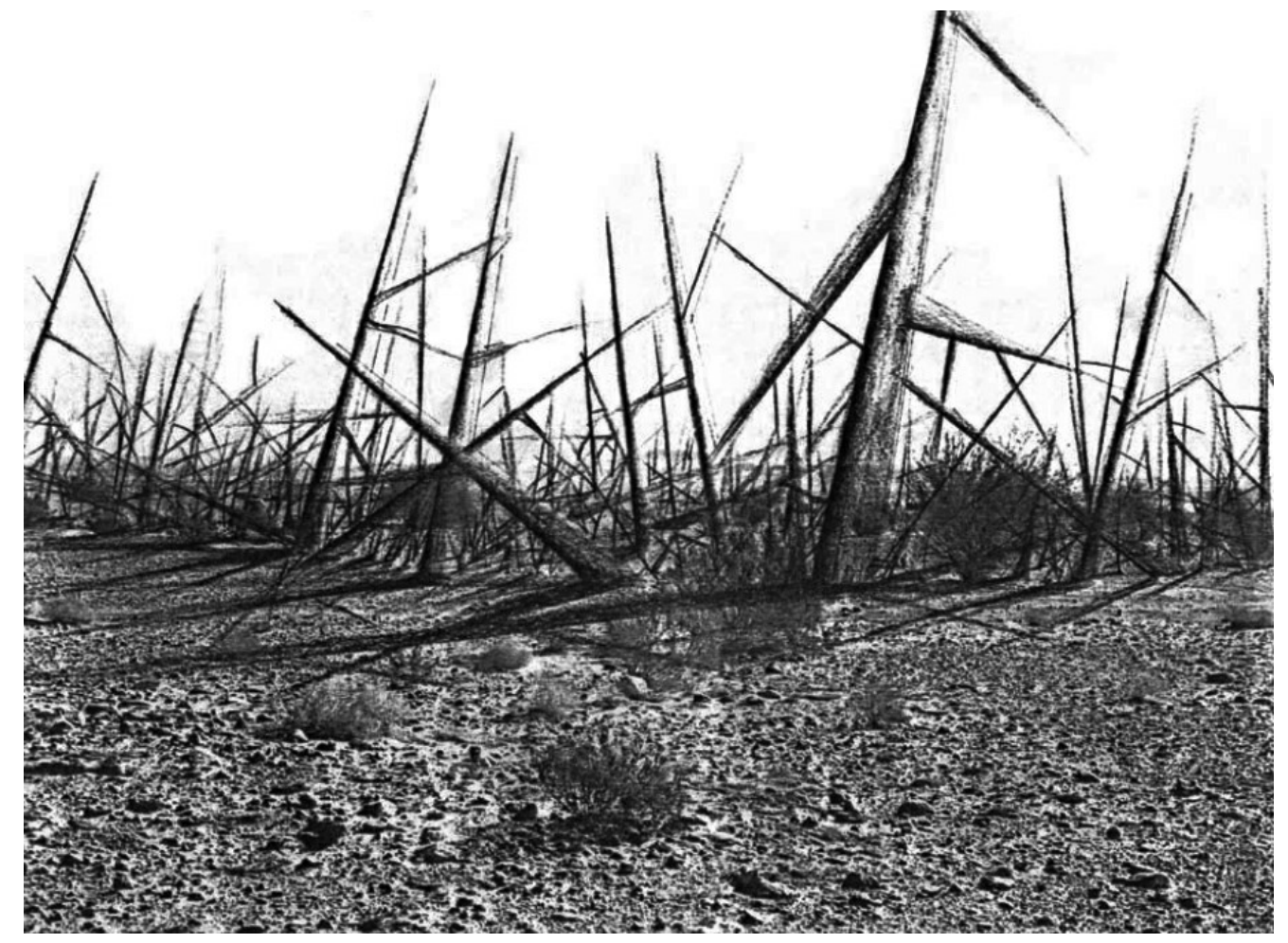

Fig. 1 Landscape of Thorns. Artist's impression of markers to deter intrusion into the WIPP site. Concept by Michael Brill, artwork by Safdar Abidi, 1991. Courtesy of BOSTI Associates. Used with kind permission. 


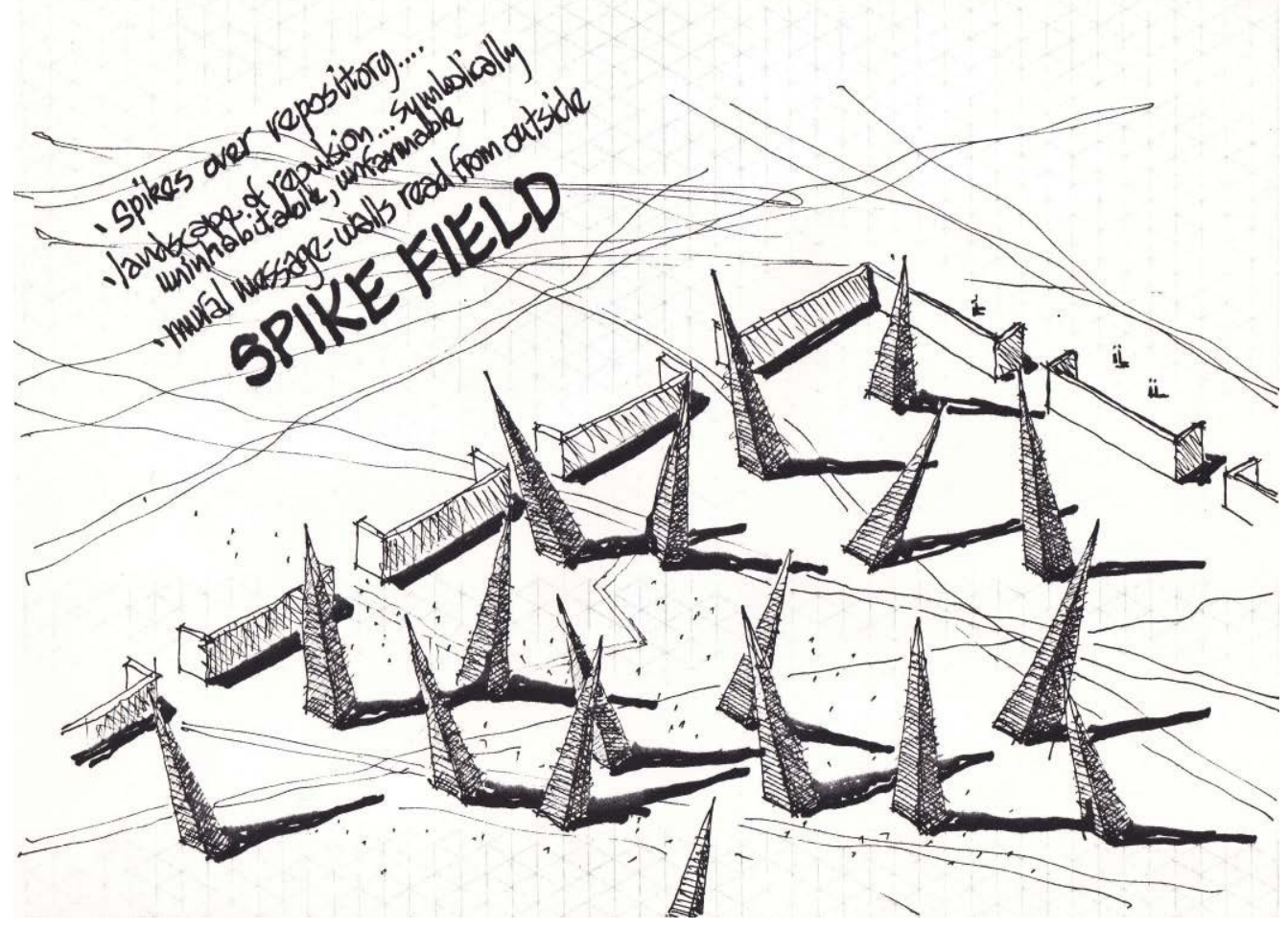

Figure 2. Spikes Bursting Through Grid. Artist's impression of markers to deter intrusion into the WIPP site. Concept by Michael Brill, artwork by Safdar Abidi, 1991. Courtesy of BOSTI Associates. Used with kind permission. 


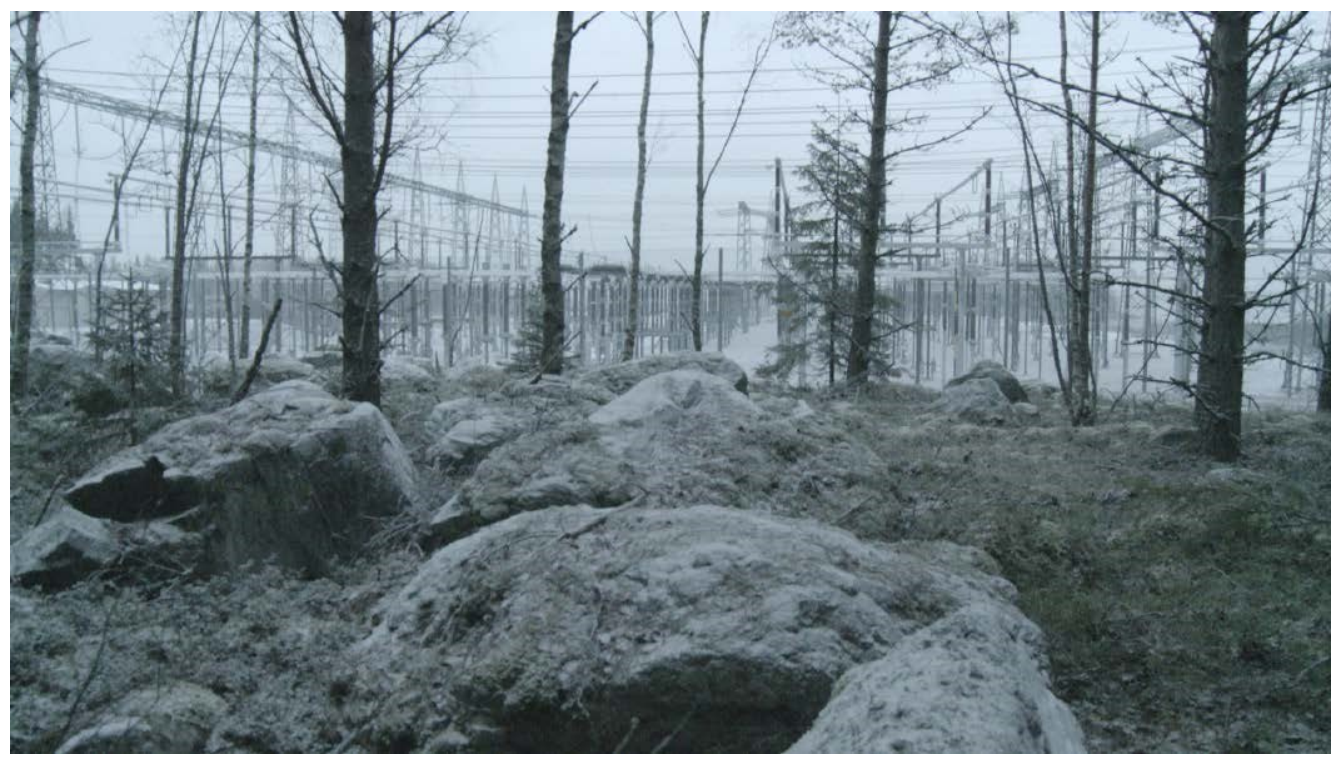

Figure 3. ONKALO above-ground. Still from Into Eternity. Courtesy of Michael Madsen. Cinematography by Heikki Färm. Produced by Magic Hours Films. Used with kind permission. 


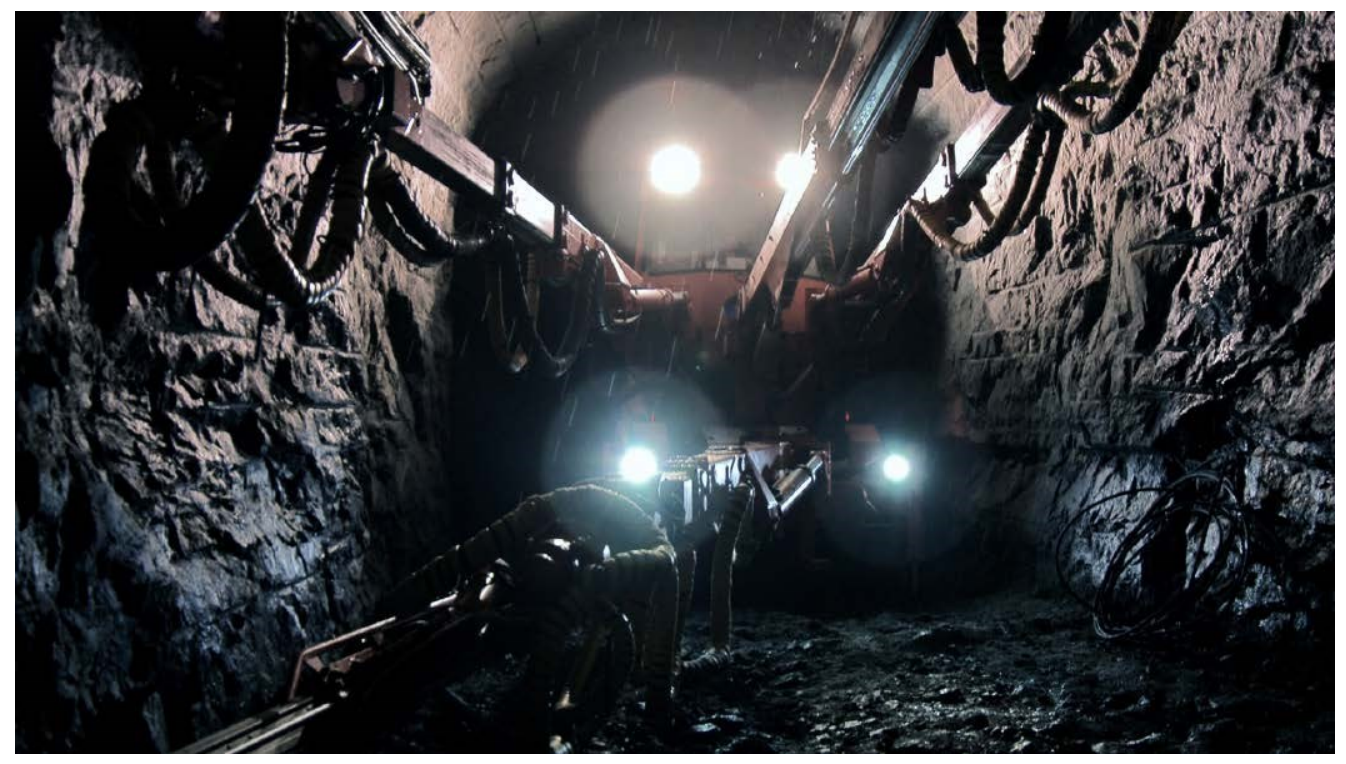

Figure 5. Work on the construction of the repository at ONKALO. Still from Into Eternity. Courtesy of Michael Madsen. Cinematography by Heikki Färm. Produced by Magic Hours Films. Used with kind permission. 


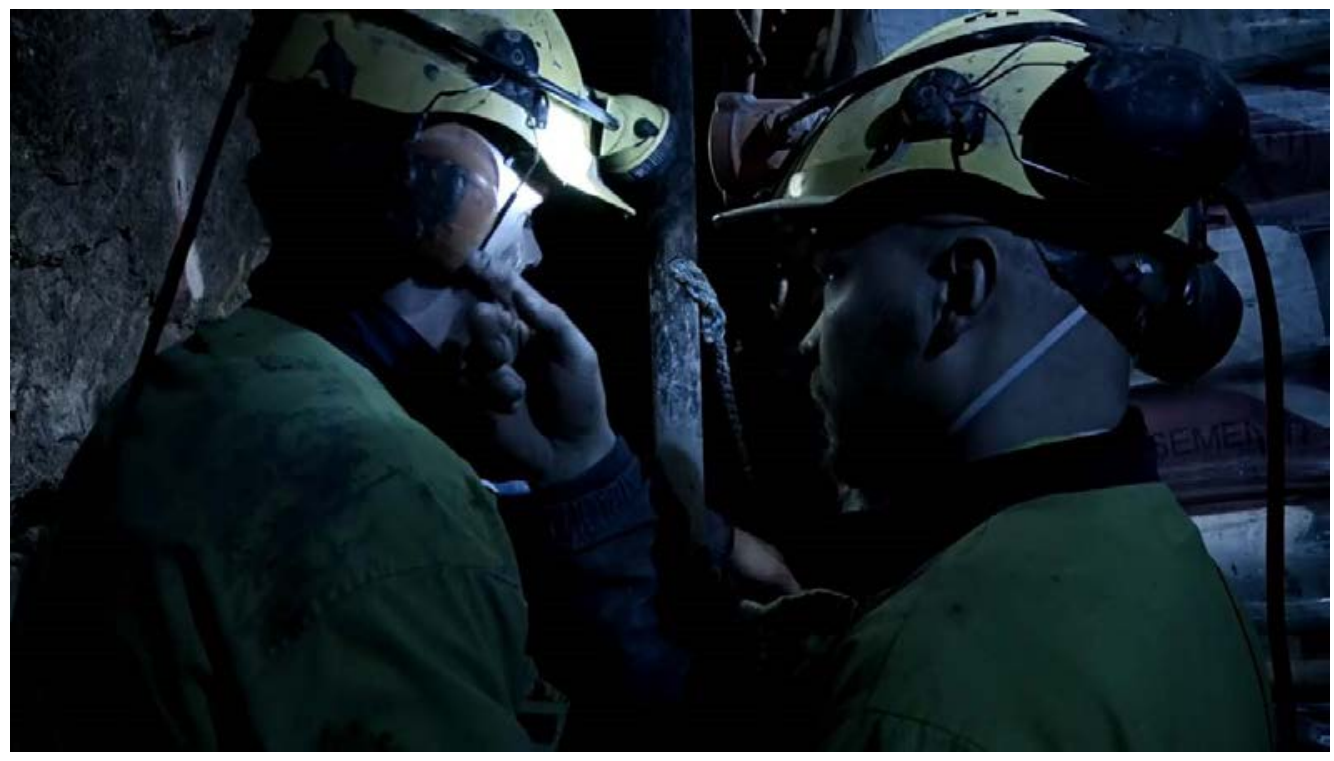

Figure 6. Vulnerability and care. Still from Into Eternity. Courtesy of Michael Madsen.

Cinematography by Heikki Färm. Produced by Magic Hours Films. Used with kind permission. 